\title{
Discurso de reconocimiento a la calidad de Profesor Emérito del profesor Mario Ramírez Necochea ${ }^{1}$
}

\author{
Speech on recognition of the quality of Professor Emeritus to Professor Mario Ramírez. \\ Necochea
}

\section{Maricruz Gómez de la Torre Vargas}

maricruz@derecho.uchile.cl

Doctora en Derecho, Universidad Complutense de Madrid. Vicedecana de la Facultad de Derecho de la Universidad de Chile.

Señoras y señores,

El señor Decano me ha pedido que lo subrogue en esta ceremonia, debido a mi cercanía con el profesor Mario Ramírez Necochea. Agradezco mucho su deferencia.

La calidad de emérito es concedida por la Universidad, como el nombre de la distinción lo señala, ex - mérito, es decir, por o en razón del mérito, luego de desarrollarse una destacada carrera académica. En el caso de la Universidad de Chile, el mérito que reconoce en sus profesores no es solo el de haber cumplido una cierta cantidad de años dedicadas a la enseñanza. Básicamente, es el mérito de encarnar el espíritu universitario, con profunda vocación pública, entregándose a la producción y difusión del conocimiento al servicio de Chile.

Es una satisfacción tener la posibilidad de celebrar, junto a su familia, el otorgamiento, por parte de nuestra Universidad, de la calidad de Profesor Emérito al profesor Ramírez Necochea.

Cuando el Decano asumió su mandato, en mayo de 2015, una de sus preocupaciones fue que don Mario pudiera recibir este reconocimiento. Por haber sido su alumno, fue testigo de su calidad humana y docente. Fue una carrera contra el tiempo, porque don Mario ya se encontraba enfermo. Con el valioso apoyo del señor Rector, la señora Vicerrectora de Asuntos Académicos y el Consejo Universitario pudimos tramitar el otorgamiento de esta distinción, que él alcanzó a conocer. Cuando le llevamos a su casa, junto a la profesora María Nora González, el acuerdo del

1 Discurso pronunciado en el acto de homenaje al Prof. Mario Ramírez Necochea efectuado el jueves 9 de marzo del 2017 en el Aula Magna de la Facultad de Derecho de la Universidad de Chile, y que contó con la presencia del señor Rector de la Universidad, del Decano de la Facultad de Derecho, de una serie de autoridades gubernamentales y académicas, de familiares del Prof. Ramírez Necochea y de alumnos de la Facultad. 
Consejo en que le concedían la distinción de Profesor Emérito, don Mario se alegró, y nos dijo “yo estoy muy enfermo, que lo reciban mis hijos". Es el pedido que hoy estamos cumpliendo.

Mario Ramírez Necochea fue un jurista y profesor de vanguardia, reconocido en Chile y en el extranjero. Largo sería mencionar sus méritos académicos y profesionales, o los títulos de sus obras. También su pasión por el ajedrez, actividad que lo unía entrañablemente con los alumnos.

Quienes tuvimos el privilegio de conocerlo sabemos que en don Mario sobresalían cualidades fundamentales.

En primer lugar, su hombría de bien, que lo hacía actuar con rectitud, transparencia y solidaridad con sus pares y discípulos. Por lo mismo, no permitía que las diferencias políticas o ideológicas afectaran su percepción como académico.

En ese sentido, pedí al profesor más antiguo del Departamento, don Mario Arnello, quien fue además su amigo, que describiera su relación con don Mario Ramírez. Respondió que "tenía una vocación de servicio público, volcada fundamentalmente a la docencia. Su generosidad no le permitía hacer distingos entre opiniones políticas o doctrinarias con persona alguna. Él estaba al servicio de una misión, que cumplía con responsabilidad, eficiencia y altura de miras".

Otra destacable cualidad suya, a mi juicio, era el entusiasmo con que trataba los temas de su disciplina y los grandes temas de interés nacional. Para él, el mérito era lo fundamental, y no toleraba la discriminación ni el sectarismo. Había sufrido en carne propia los efectos de la polarización política, y no quería que Chile pasara otra vez por eso.

Esto entronca con un tercer rasgo suyo: el afán genuino en reconocer el mérito de las mujeres académicas.

En la Facultad, no aceptaba que las mujeres estuvieran destinadas a ocupar jerarquías secundarias. En su Departamento de Derecho Internacional, siempre apoyó y promovió la carrera de las académicas jóvenes. Es algo que bien saben profesoras como Gilda Cicci, Carola Canelo, Rita Lages, Elina Mereminskaya, Ana María Moure, y otras.

Le pedí a Elina, quien fuera una de sus discípulas en la Facultad -que no ha podido estar presente hoy, por encontrarse fuera del país-, que lo describiera. Ella señala que "el profesor Ramírez fue mi mentor y amigo durante mis primeros años en Chile. Creyó en mí cuando apenas se me entendía el castellano. Me abrió las puertas del Departamento de Derecho Internacional, en el cual terminé pasando hasta doce horas al día, donde compartíamos temas de interés profesional, y también la adicción por los dulces, las paltas y el vino tinto. Tengo grabadas sus historias sobre su pasado como marino, su viaje a la Unión Soviética, su encuentro con quien después se convertiría en el Papa Francisco. Don Mario fue un caballero, en el verdadero sentido de la palabra: quería ver a las mujeres empoderadas y exitosas. Transparente, cálido e íntegro, una tremenda persona, y así lo recordaré”. 
Todas estas cualidades hicieron del profesor Ramírez Necochea un gran señor y un gran académico. Prueba de ello es el libro que presentamos hoy en su homenaje, que reúne las contribuciones de destacados académicos nacionales y extranjeros, y de ayudantes del Departamento de Derecho Internacional. Agradezco a todos los autores su participación, al profesor Picand, que coordinó la primera etapa del libro, y muy especialmente a la ministra Marisol Peña, por aceptar presentarlo.

Para terminar, agradezco a la familia del profesor Ramírez Necochea su asistencia y colaboración en esta ceremonia, y la presencia de todos ustedes aquí esta tarde.

Muchas gracias. 